\title{
Pricing Decision for a Supply Chain with Social-responsibility Concerned Retailer

\author{
Wei-Min MA ${ }^{\mathrm{a}}$,Yan-Li CAI ${ }^{\mathrm{b}}$, Rong CHENG ${ }^{\mathrm{c}, *}$ \\ School of Economics and Management, Tongji University, Shanghai, China \\ amawm@tongji.edu.cn, ${ }^{\mathrm{b}}$ cylpp111@163.com, ${ }^{\mathrm{c}} 13667737255 @ 163 . c o m$ \\ *Corresponding author
}

\begin{abstract}
Keywords: Pricing decision, Corporate social responsibility, Stackelberg game, Governments' subsidies.

Abstract. This paper analyses the pricing decision of a single-manufacturer-single-retailer supply chain, where the retailer exhibits corporate social responsibility(CSR). One centralized and two decentralized game models(manufacturer-Stackelberg game and retailer-Stackelberg game) are built to examine the impact of undertaking(CSR) on the profitability of the supply chain members as well as the whole channel. It is found that no matter who dominates the channel, the retailer always suffers from CSR when it is a profit-maximizer. Our finding verifies that not only manufacturers but also the retailer would be not willing to take(CSR) unless governments' subsidies or market rewards can compensate them for doing so. Interestingly when social responsibility is concerned, we show that a dominate retailer will be best off by taking(CSR). Therefore, we suggest that a powerful retailer should offer to take(CSR) strategically and otherwise for a weak one.
\end{abstract}

\section{Introduction}

The profit-maximized firms play vital roles in the economic development, on the other hand, they consume a large amount of natural resources and even cause great pollution to the environment. In recent years, as the awareness of environmental protection and sustainable development has been dramatically increasing, corporations are supposed to take more and more responsibility of environmental protection[1,2,3]. Therefore, abundant research interests are attracted into corporate social responsibility(CSR). Although without a universally accepted definition, CSR usually refers to a firm's corporate behavior that displays social and ethical responsibility to its array of stakeholders (eg. customers, employees, communities, supply chain members, etc) [4].

CSR issues surrounding supply chains have only recently come to the fore, notably [5]. Although supply chain practitioners have been slow to adopt CSR considerations, the concept of corporate social responsibility in the supply chain is increasing in importance [6]. Corporate social responsibility proved to increase trust in and support for organizationsby effecting their buying behavior and then enhancing brand image [7], corporate reputation and marketing sales [8]. Corporations' involvement in CSR unavoidably causes costs, even sometimes increases consumers' willingness-to-pay, changing the market demand function [9]. Whether supply members benefit from or suffer from exhibiting CSR is the focus of the extant research. However, the main conclusions on the CSR issue are made based on the assumption that manufacturers exhibits CSR. To the best of our knowledge, there are few studies that examine the scenario where retailers exhibits CSR. The retailer, as the part most close to customers in the supply chain, is counting a great deal in a consumer oriented market.In the recent decades, more and more giant retailers like Walmart, Carrefour and even some e-tailers, such as Alibaba, Amazon, have been showing up and have attached high importance to CSR.

This paper intends to explore a supply chain consisting of a manufacturer and a socially responsible retailer. It is widely observed that the main target in supply chain CSR is at the manufacturer's side [10]. This paper assumes that the retailer is consumer oriented and powerful enough to exhibit CSR. Besides pure-profit-maximization motivation, the retailer devotes itself to the intent on swelling stakeholder's welfare by exhibiting CSR. Two cases, the retailer is socially 
concerned in a manufacturer-Stackelberg game and in the other, the socially responsible retailer itself is playing the role as a leader in the whole channel. The cost of CSR and the consumer surplus are adopted into our model at the same time which has not been explored in previous work. In Stackelberg-game setting, we analyze effects of CSR on the profits of the channel members in different power structures, both in centralized decision and in decentralized decision.

The rest of the paper is organized as follows. Section 2 summarizes the literature related to CSR attribution in supply chain. Section 3 is problem description and Section 4 the model is developed and relevant results for supply chain with socially concerned retailer are derived. Finally, in Section 5 some concluding remarks are drawn and direction of future research are provided.

\section{Literature Review}

CSR has been put forward by Bowen [11] and once central in the expansive debate about the purpose of business organizations $[12,13,14]$. Defined as "actions that appear to further some social good, beyond the interests of the firm and that which is required by law"[15], CSR is reflected in a variety of organizational practices that are intended to serve stakeholders beyond the firm's owners, consisting of employees, customers, communities, and whole society. In the current global business environment, CSR now is a determining factor in consumer and client choice. Thus, many researches are gravitated to CSR on specific disciplines such as marketing [16,17], organizational behavior, human resource management, corporate operations [18].

Prior research has assessed returns of CSR efforts by examining financial performance by empirical analysis. The majority of these studies show a positive effect on consumers' affective and behavioral response $[19,20]$. A consistent finding regarding the institutional-level outcomes of CSR initiatives is an improvement in a firm's reputation [21,22,23], better financial performance [24,25], risk management [26,27] and customer loyalty [28]. Furthermore, the increased focus on the environment is significantly influencing supply chains and CSR topics on supply chains emerge recently, in the context of conceptual and survey studies [29,30]. Legal requirements and increasing consumer preferences make suppliers, manufacturers and distributors responsible for their products beyond their sales[31]. Although the positive effect of CSR is well-established in the investigation of empirical analysis, CSR activities afflicted with cost is rarely conducted. $\mathrm{Ni}$ and $\mathrm{Li}$ have developed a two-echelon supply Chain by assuming that each channel member has individual CSR cost [32]. They have examined the effects of strategic interactions between the channel members under game theoretic setting. However, there is hardly research integrating the cost of CSR and the effect of CSR into a channel at the same time.

This paper will explore a supply chain consisting of a manufacturer and retailer, in which the retailer is concerned with corporate social responsibility. The objectives of the paper differ from the prior works as follows. Firstly, previous researches have explored CSR cost, effects of CSR on supply chain and channel coordination discretely. But there are few paper concerning the cost of CSR and the effect of CSR simultaneously. Xiao, Yang [33] and Tsay, Agrawal [34]assume service cost functions in the same quadratic form that is independent of selling quantity, while Gurnani et al. [35] introduce a quality cost function with both sales-irrelevant and sales-relevant components. In this paper, for our CSR cost function, the quadratic form is related to the previous work[37,38]. It has been noted that the quality level also has an impact on the variable costs[39]. So we take the cost for undertaking CSR into consideration in the form of variable costs. Secondly, it is widely observed that the main target in supply chain CSR is at the manufacturer's side[13]. We assume that the retailer prefers the CSR and consider different kinds of case, centralized decision and decentralized decision, in which either a dominant manufacturer or retailer is conducted. It is well established that a firm's CSR is accounted through the consumer surplus of its stakeholders[36,36,37,38,39]. The objectives of the paper is to discuss the effect of retailer's CSR on the channel profit after incorporating the cost and also when socially responsible retailer leads the channel by adopting price makeup strategy, how the CSR will affect its strategy considering the CSR cost. 


\section{Problem Description}

In this paper, we consider a manufacturer-retailer supply chain that operates for a single product. The manufacturer produces the product at a unit cost $c$ and supplies it to the retailer in a single lot at a wholesale price $w_{m}$ to satisfy customer's demand. The retailer sales the product to customers at the pricep.

Demand function at the retailer's end is fairly common in literature. It is linear in retail price and is of the form $\mathrm{D}=a-b p$, where $a>0$ is the market potential and $b>0$ is customer's price sensitivity. This simple monopoly structure allows analyzing the effects of CSR on the channel members. The following notations in Table 1 are used in developing the model.

Table 1 Notations

\begin{tabular}{|c|l|}
\hline$p$ & unit selling price of the retailer \\
\hline$w_{m}$ & unit wholesale price of the manufacturer \\
\hline$p_{c}$ & unit selling price of the supply chain in centralized decision making \\
\hline c & marginal production cost of the manufacturer \\
\hline$q_{c}$ & order quantity of the product in centralized decision making \\
\hline$P P_{c}$ & pure profit of centralized channel \\
\hline$C S_{c}$ & consumer surplus of centralized channel \\
\hline$C S_{d s}^{m}$ & consumer surplus with manufacturer leading the channel \\
\hline$C S_{d s}^{r}$ & consumer surplus with retailer leading the channel \\
\hline$\pi_{c}$ & profit function of centralized channel \\
\hline$\pi_{m}^{m}$ & profit function of the manufacturer with manufacturer leading the channel \\
\hline$\pi_{r}^{m}$ & profit function of the retailer with manufacturer leading the channel \\
\hline$\pi_{m}^{r}$ & profit function of the manufacturer with retailer leading the channel \\
\hline$\pi_{r}^{r}$ & profit function of the retailer with retailer leading the channel \\
\hline$U_{r}$ & retailer's raised price based on the wholesale price of manufacturer \\
\hline$\theta$ & the degree of consumer’s preference to manufacture's CSR \\
\hline$\tau$ & the marginal cost of the manufacture’s CSR, $\tau>0$ \\
\hline
\end{tabular}

We assume the retailer invests in CSR and aligns its CSR goal with channel performance. In modeling and analysis, we consider effects of consumers' preference to the retailer's socially responsibility in the form of consumer surplus as some previous work [36,38]and we also incorporate the cost of manufacturer for exhibiting CSR into the function of consumers' preference $\theta$. If consumer is in favor of CSR, he or she will to pay higher price for the product, so it is reasonable to incorporate consumer surplus in profit of the retailer as the effect of CSR practice. The consumer surplus is the difference between the maximum price that the consumers are willing to pay for a product and the market price that they actually pay for the product. Thus, the consumer surplus is:

$$
\int_{p_{\min }}^{p_{\max }} q d p=\int_{(a-q) / b}^{a / b}(a-b p) d p=\frac{q^{2}}{2 b}
$$

$0 \leq \theta \leq 1, \theta=0$ implies the consumer is totally out of preference to manufacture's CSRi.e.the firm is pure profit maximizer, $\theta=1$ implies consumers' complete preference to manufacture's CSR, i.e. indicates that the firm is the perfect welfare maximizer. We define the marginal cost as $\tau \theta^{2}$ for exhibiting CSR which is dependent of the production quantity.If $\theta$ is the preference of consumer to be socially responsible, then it incorporates $\frac{\theta q^{2}}{2 b}$ as consumer surplus intoretailer's profit. 


\section{Model Analysis}

\section{Centralized Decision}

The socially concerned retailer's objective is to maximize the traditional profit and a share of consumer surplus that accrues to its stakeholders. The manufacturer is pure profit maximizer. Assume that the manufacture and the retailer are willing to cooperate and want to implement joint decision. So, there is a single marketing channel in which a product is produced and then is sold to the customers at a retail price $p_{c}$. Also, the channel practices CSR.Thus, some consumer surplus is accumulated from the stakeholders in the channel. The profit function of the channel is:

$$
\begin{gathered}
P P_{C}=\left(p_{c}-c-\tau \theta^{2}\right)\left(a-b p_{c}\right) \\
C S_{C}=\frac{\theta}{2 b}\left(a-b p_{c}\right)^{2}(2) \\
\pi_{c}=\left(p_{c}-c-\tau \theta^{2}\right)\left(a-b p_{c}\right)+\frac{\theta}{2 b}\left(a-b p_{c}\right)^{2}
\end{gathered}
$$

Using necessary condition, $\frac{\mathrm{d} \pi_{c}}{\mathrm{~d} p_{c}}=0$, for the existence of the optimal solution, optimal value of $p_{c}$ can be found in Table 2. Also, the optimal value of order quantity, pure profit and total profit are presented in Table 2. We notice that $\frac{d^{2} \pi_{c}}{d^{2} p_{c}}=(\theta-2) b<0$, i.e., $p_{c}^{*}$ provides the optimal value of $\pi_{c}$. To simply the formulation, we denote $k=\left[a-b\left(c+\tau \theta^{2}\right)\right]$ and to make the following analysis meaningful, we assume $k>0, \tau<\left.\min \frac{a-b c}{b \theta^{2}}\right|_{\theta=1}=\frac{a-b c}{b}$ to guarantee the system-wide optimal profit and CSR performance for the supply chain to be greater than zero.

Observe that $\frac{d P P_{C}}{d \theta}=-4 b \tau \theta k-\frac{\theta}{b(2-\theta)^{3}} k^{2}<0$, CSR attribution of the retailer directly influence its pure profit objective. More particularly, CSR goal of the retailer is inversely related to its pure profit. If the retailer puts more emphasis on CSR, then its traditional profit decreases. Observe that $\frac{d \pi_{c}}{d \theta}=\frac{k[k-4 b \tau \theta(2-\theta)]}{2 b(2-\theta)^{2}}$, we denote $M_{0}=k-4 b \tau \theta(2-\theta)=3 b \tau \theta^{2}-8 b \tau \theta+a-b c, \Delta 1=$ $(-8 b \tau)^{2}-12 b \tau(a-b c)=4 b \tau(16 b \tau-3 a+3 b c)$, we can get the following Proposition1:

Table 2 Optimal value in centralized and decentralized decision making $\left(k=\left[a-b\left(c+\tau \theta^{2}\right)\right]\right)$

\begin{tabular}{|c|l|l|l|l|l|}
\hline Optimal Value & Centralized Decision & MD-m & MD-r & RD-m & RD- \\
\hline$\omega_{m}$ & - & $\frac{a+b\left(c-\tau \theta^{2}\right)}{2 b}$ & - & $\frac{a+b\left[(3-\theta) c-\tau \theta^{2}\right]}{b(4-\theta)}$ & - \\
\hline$U_{r}$ & - & - & - & - & $\frac{(2-\theta) a-b\left[(2-\theta) c-2 \tau \theta^{2}\right.}{b(4-\theta)}$ \\
\hline $\mathrm{p}$ & $\frac{(1-\theta) a+b\left(c+\tau \theta^{2}\right)}{b(2-\theta)}$ & & $\frac{(3-2 \theta) a+b\left(c+\tau \theta^{2}\right)}{2 b(2-\theta)}$ & - & $\frac{(3-\theta) a+b\left(c+\tau \theta^{2}\right)}{b(4-\theta)}$ \\
\hline $\mathrm{q}$ & $\frac{k}{2-\theta}$ & $\frac{k}{2(2-\theta)}$ & $\frac{k}{2(2-\theta)}$ & $\frac{k}{4-\theta}$ & $\frac{k^{2}}{4-\theta}$ \\
\hline $\mathrm{PP}$ & $\frac{(1-\theta) k^{2}}{b(2-\theta)^{2}}$ & $\frac{k^{2}}{4 b(2-\theta)}$ & $\frac{(1-\theta) k^{2}}{4 b(2-\theta)^{2}}$ & $\frac{k^{2}}{b(4-\theta)^{2}}$ & $\frac{k^{2} \theta}{2 b(4-\theta)^{2}}$ \\
\hline $\mathrm{kS}$ & $\frac{k^{2} \theta}{2 b(2-\theta)^{2}}$ & $-\frac{k^{2} \theta}{8 b(2-\theta)^{2}}$ & - & $\frac{k^{2}}{2 b(4-\theta)}$ \\
\hline$\pi$ & $\frac{\mathrm{k}^{2}}{2 b(2-\theta)}$ & $\frac{k^{2}}{4 b(2-\theta)}$ & $\frac{\mathrm{k}^{2}}{8 b(2-\theta)}$ & $\frac{k^{2}}{b(4-\theta)^{2}}$ & $\frac{1}{2 b}$ \\
\hline
\end{tabular}

Proposition 1. (i)if $(16 b \tau-3 a+3 b c)>0$, i.e., $\tau>\frac{3 a-3 b c}{16 b}$, we can get the root $\theta_{1}, \theta_{2}$ of $\Delta 1$, $\theta_{1}=\frac{4 \mathrm{~b} \tau-\sqrt{\mathrm{bt}(16 \mathrm{~b} \tau-3 \mathrm{a}+3 \mathrm{bc})}}{3 \mathrm{~b} \tau}, \theta_{2}=\frac{4 \mathrm{~b} \tau+\sqrt{\mathrm{bt}(16 \mathrm{~b} \tau-3 \mathrm{a}+3 \mathrm{bc})}}{3 \mathrm{~b} \tau}$.

If $\theta_{1}<1$, i.e., $b \tau(5 b \tau-a+b c)>0$, i.e., $\tau>\frac{a-b c}{5 b}$, when $0 \leq \theta<\theta_{1}$, then $M_{0}>0$, i.e., $\frac{d \pi_{c}}{d \theta}>0$ and when $0<\theta \leq \theta_{1}$, then $M_{0}<0$, i.e., $\frac{d \pi_{c}}{d \theta}<0$. Also, if $\theta_{1}>1$, i.e., $\frac{3 a-3 b c}{16 b}<\tau<$ 
$\frac{a-b c}{5 b}$, when $0 \leq \theta \leq 1$, then $M_{0}>0$, i.e., $\frac{d \pi_{c}}{d \theta}>0$.

(ii)if $(16 b \tau-3 a+3 b c) \leq 0$, i.e. $\tau \leq \frac{3 a-3 b c}{16 b}$, when $0 \leq \theta \leq 1$, then $M_{0}>0$, i.e., $\frac{d \pi_{c}}{d \theta}>0$.

Due to the aforesaid assumption $k>0$,in a centralized decision channel in which we incorporate the cost of retailer's exhibiting CSR, CSR goal of the retailer is inversely related to the pure profit. If the retailer puts more emphasis on CSR then its traditional profit decreases, which is the same as a supply chain not considering the cost. When the cost of retailer's to be socially responsible $\frac{a-b c}{5 b}<\tau<\frac{a-b c}{b}$, the channel profit increases with respect to CSR in the range of $\left[0, \theta_{1}\right), \theta_{1}$ is the minor root of $\Delta 1$ and otherwise if $\theta$ belongs to $\left(\theta_{1}, 1\right]$; In other words, if the channel holds higher CSR cost then its profit will decrease when it pursues higher level of CSR. When $\tau<\frac{a-b c}{5 b}$, i.e. when the retailer controls its cost more than less than $\frac{a-b c}{5 b}$, the channel profit will increase with the rising sense of CSR. Because the consumer surplus can make up the loss of pure profit. When the cost of being social responsibility is considered into the supply chain, the relation between profit of the channel and the degree of consumer preference oriented is more complex compared with a simple channel.

\section{Decentralized Decision}

\section{Manufacturer-Stackelberg Game}

In a manufacturer-retailer supply chain, “dominant” means that a supply chain member, has the power of controlling or influencing another member's decisions [40]. When the channel members operate independently and optimize their individual goals, it is essentially a non-cooperative decision making process, where the manufacturer is the leader of the channel and the retailer is the follower. The CSR goal is the retailer's own. We consider manufacturer-Stackelberg game. The manufacturer has the initiative and can enforce its own strategy on the retailer. The manufacturer initiates first move and the retailer responds by playing the best move consistent with all available information. The objective of the Manufacturer is to design its own strategy that maximize its profit after considering all possible moves the retailer can adopt. We use backward induction to find the sub-game perfect solution of the game. In this condition, the profit functions of the channel members are:

$$
\begin{aligned}
\pi_{m}^{m} & =\left(w_{m}-c\right)\left(a-b p^{m}\right) \\
\pi_{r}^{m} & =\left(p-w_{m}-\tau \theta^{2}\right)\left(a-b p^{m}\right) \\
C S_{d s}^{m} & =\frac{\theta}{2 b}\left(a-b p^{m}\right)^{2}
\end{aligned}
$$

Since the retailer is engaged in CSR, its total profit, i.e., pure profit plus a share of consumer surplus is:

$$
V_{r}^{m}=\left(p-w_{m}-\tau \theta^{2}\right)\left(a-b p^{m}\right)+\frac{\theta}{2 b}\left(a-b p^{m}\right)^{2}
$$

This is a two stage game. Using backward induction the optimal solution can be found and are presented in Table 2. Observe that $\frac{d \pi_{r}^{m}}{d \theta}=\frac{k[-\theta k-4 b \tau \theta(1-\theta)(2-\theta)]}{4 b(2-\theta)^{3}}<0$, without a doubt, the retailer's pure profit decreases with increasing sense of social responsibility. Also, $\frac{d \mathrm{~V}_{r}^{m}}{d \theta}=\frac{k[k-4 b \tau \theta(2-\theta)]}{8 b(2-\theta)^{2}}, \frac{\mathrm{d} \pi_{m}}{d \theta}=\frac{k[k-4 b \tau \theta(2-\theta)]}{4 b(2-\theta)^{2}}$, if we denote $M_{1}=M_{0}=k-4 b \tau \theta(2-\theta)$, it is noticed that the profit of retailer and manufacturer of manufacturer dominant supply chain respond to the CSR in the same way as that in centralized channel. Note that $\frac{d w_{m}}{d \theta}=-\tau \theta<0$, the retailer's increasing CSR will get the manufacturer's wholesale decreased.

Note that $\pi_{m}^{m}+v_{r}^{m}-\pi_{c}=\frac{-k^{2}}{8 b(2-\theta)}<0$, for $0 \leq \theta \leq 1$, i.e., the channel is not coordinated and double marginalization exists in the manufacturer-leading channel. As a result, we obtain the 
following Proposition 2:

Proposition 2. In a non-cooperative decision making process, although the manufacturer is strong enough to be the leader of the channel, it will be effected by retailer's goal of CSR. Its wholesale price will decrease with the rising sense of retailer's CSR. And just as the centralized decision, CSR goal of the retailer is inversely related to retailer's pure profit. The total profit of the manufacturer and the retailer in the manufacturer leading channel performs the same as that in the centralized decision.

\section{Retailer-Stackelberg game}

Over past 20 years, Circulation Industry has ushered in a huge change. One focus of the transformation is embodied with the shift of dominance from the manufacturer to the retailer in supply chain. "The retailing industry today is increasingly dominated by large, centrally managed power retailers"[41], such as Walmart, Carrefour. They are in the position of leading especially when some small manufactures try to make inroad to the huge competitive market. A large number of study has gravitated towards this area of retailer dominance and the phenomenon of power in the distribution channels has been given rather regular, empirical attention in the marketing literature [42].

When the channel members operate independently and optimize their individual goals, it is essentially a non-cooperative decision making process, where the retailer is the leader of the channel. The CSR goal is the retailer's own.Here, after the dominant retailer leads by declaring a markup $U_{r}$ of unit product [43], the manufacturer responds by quoting the unit wholesale price $w_{m}$. Accordingly the manufacturer identifies its own strategy. It is Stackelberg games between the manufacturer and the retailer. The profit functions of the channel members are:

$$
\begin{aligned}
\pi_{m}^{r} & =\left(\omega_{m}-c\right)\left[a-b\left(\omega_{m}+U_{r}\right)\right] \\
\pi_{r}^{r} & =\left(U_{r}-\tau \theta^{2}\right)\left[a-b\left(\omega_{m}+U_{r}\right)\right] \\
C S_{d s}^{r} & =\frac{\theta}{2 b}\left[a-b\left(\omega_{m}+U_{r}\right)\right]^{2}
\end{aligned}
$$

The same as the previous case, since the retailer is engaged in CSR, its total profit, i.e., pure profit plus a share of consumer surplus is:

$$
V_{r}^{r}=\left(U_{r}-\tau \theta^{2}\right)\left[a-b\left(\omega_{m}+U_{r}\right)\right]+\frac{\theta\left[a-b\left(\omega_{m}+U_{r}\right)\right]^{2}}{2 b}
$$

We use backward induction to find the sub-game perfect solution of the game as shown in Table 2.Observe that $\frac{d \pi_{r}^{r}}{d \theta}=\frac{k[-2 k-4 b \tau \theta(4-\theta)]}{b(4-\theta)^{3}}<0$, as expected, the manufacturer's pure profit decreases with increasing CSR.

Also, $\frac{d \pi_{m}^{r}}{d \theta}=\frac{k[k-4 b \tau \theta(4-\theta)]}{b(4-\theta)^{3}}, \frac{d V_{r}^{r}}{d \theta}=\frac{k[k-4 b \tau \theta(4-\theta)]}{2 b(4-\theta)^{2}}$, we denote $M_{3}=k-4 b \tau \theta(4-\theta), \Delta 3=$ $b \tau(256 b \tau-12 a+12 b c)$, we can get the following Proposition 3:

Proposition 3.(i)if $(256 b \tau-12 a+12 b c)>0$, i.e., $\tau>\frac{3 a-3 b c}{64 b}$, we can get the roots $\theta_{5}$ and $\theta_{6}$ of $M_{3}=0, \theta_{5}=\frac{16 b \tau-\sqrt{b \tau(256 b \tau-12 a+12 b c)}}{6 b \tau}, \theta_{6}=\frac{16 b \tau+\sqrt{b \tau(256 b \tau-12 a+12 b c)}}{6 b \tau}$.

If $\theta_{5}<1$, i.e., $\tau>\frac{a-b c}{13 b}$, when $0 \leq \theta<\theta_{5}$, then $M_{3}>0$, i.e., $\frac{d \pi_{m}^{r}}{d \theta}>0$ and also $\frac{d V_{r}^{r}}{d \theta}>0$; when $\theta_{5}<\theta \leq 1$, then $M_{3}<0$, i.e., $\frac{d \pi_{m}^{r}}{d \theta}<0$ and also $\frac{d V_{r}^{r}}{d \theta}<0$; Also, if $\theta_{5}>1$, i.e., $\tau<\frac{a-b c}{13 b}$, when $0 \leq \theta \leq 1$, then $M_{3}>0$, i.e., $\frac{d \pi_{m}^{r}}{d \theta}>0$ and also $\frac{d V_{r}^{r}}{d \theta}>0$.

(ii) If $(256 b \tau-12 a+12 b c) \leq 0$, i.e., $\tau<\frac{3 a-3 b c}{64 b}$, when $0 \leq \theta \leq 1$, then $M_{3}>0$, i.e., $\frac{\mathrm{d} \pi_{\mathrm{m}}^{\mathrm{r}}}{\mathrm{d} \theta}>0$ and also $\frac{\mathrm{d} V_{\mathrm{r}}^{\mathrm{r}}}{\mathrm{d} \theta}>0$.

Note that $\pi_{\mathrm{m}}^{\mathrm{r}}+\mathrm{V}_{\mathrm{r}}^{\mathrm{r}}-\pi_{\mathrm{c}}=\frac{-4 \mathrm{k}^{2}}{2 \mathrm{~b}(2-\theta)(4-\theta)^{2}}<0$, for $0 \leq \theta \leq 1$, i.e., the channel is not coordinated and double marginalization exists in the retailer-dominant channel. Even the perfect welfare 
maximizing motive of the retailer does not resolve channel conflict.

Also, we notice that $\pi_{\mathrm{r}}^{\mathrm{r}}-\pi_{\mathrm{r}}^{\mathrm{m}}=\frac{\left(15 \theta^{2}-3 \theta^{3}-24 \theta+16\right) \mathrm{k}^{2}}{4 \mathrm{~b}(2-\theta)^{2}(4-\theta)^{2}}>0$, for the retailer, when it is responsible for CSR, it would better lead the whole channel for realizing its higher optimal profit.

In a channel with retailer leading, CSR goal of the retailer is inversely related to retailer's pure profit and differently the perfect welfare maximizing motive of the retailer does not resolve channel conflict, which is similar with that in manufacturer leading channel.

When the cost of retailer's to be socially responsible $\frac{a-b c}{13 b}<\tau<\frac{a-b c}{b}$, the channel profit increases with respect to CSR in the range of $\left[0, \theta_{5}\right), \theta_{5}$ is the minor root of $\Delta 3$ and otherwise if $\theta$ belongs to $\left(\theta_{5}, 1\right]$; In other words, if the retailer holds higher CSR cost then its profit will increase when it pursues higher level of CSR. When $\frac{3 a-3 b}{64 b}<\tau<\frac{a-b c}{13 b}$, i.e. when the retailer controls its cost more than $\frac{3 a-3 b}{64 b}$ and less than $\frac{a-b c}{13 b}$, the channel profit will increase with the rising sense of CSR.

We will explore how the cost of CSR effect the retailer's makeup price strategy. Notice that $\frac{d U_{r}}{d \theta}=\frac{2\left[-b \tau \theta^{2}+8 b \tau \theta-a+b c\right]}{b(4-\theta)}$, we denote $M_{4}=-b \tau \theta^{2}+8 b \tau \theta-a+b c$, when $M_{4}=0$, we can get $\Delta 4=4 b \tau(16 b \tau+b c-a)$, we can get the following Proposition 4 :

Proposition 4. (i)if $\Delta 4>0$, i.e., $\tau>\frac{a-b c}{16 b}$, we can get the roots $\theta_{7}$ and $\theta_{8}$ of $M_{4}=0$, $\theta_{7}=\frac{4 \mathrm{~b} \tau-\sqrt{\mathrm{b} \tau(16 \mathrm{~b} \tau-\mathrm{a}+\mathrm{bc})}}{\mathrm{b} \tau}, \theta_{8}=\frac{4 \mathrm{~b} \tau+\sqrt{\mathrm{b} \tau(16 \mathrm{~b} \tau-\mathrm{a}+\mathrm{bc})}}{\mathrm{b} \tau}$.

If $\theta_{7}<1$, i.e., $\tau>\frac{a-b c}{7 b}$, when $0 \leq \theta<\theta_{7}$, then $M_{4}<0$, i.e., $\frac{d U_{r}}{d \theta}<0$; when $\theta_{7}<\theta \leq 1$, then $M_{4}>0$, i.e., $\frac{d U_{r}}{d \theta}>0$; Also, if $\theta_{7}>1$, i.e., $\tau<\frac{a-b c}{7 b}$, when $0 \leq \theta \leq 1$, then $M_{4}<0$, i.e., $\frac{\mathrm{d} \mathrm{U}_{\mathrm{r}}}{\mathrm{d} \theta}<0$.

(ii)if $\Delta 4 \leq 0$, i.e. $\tau \leq \frac{\mathrm{a}-\mathrm{bc}}{16 \mathrm{~b}}$, when $0 \leq \theta \leq 1$, then $\mathrm{M}_{4}<0$, i.e., $\frac{\mathrm{d} \mathrm{U}_{\mathrm{r}}}{\mathrm{d} \theta}<0$.

When the retailer is apt to CSR and at the same time leads the channel, its makeup price strategy will be effected by its cost investing to CSR. When the margin cost of retailer's to be socially responsible $\frac{a-b c}{7 b}<\tau<\frac{a-b c}{b}$, the makeuppricedecreases with respect to CSR in the range of $\left(0, \theta_{7}\right], \theta_{7}$ is the minor root of $\Delta 4$ and otherwise if $\theta$ belongs to $\left(\theta_{7}, 1\right]$; when $\frac{a-b c}{16 b}<\tau<\frac{a-b c}{7 b}$, i.e. when the retailer controls its cost more than $\frac{a-b c}{16 b}$ and less than $\frac{a-b c}{7 b}$, the makeup price will decrease with the rising sense of CSR. It turns out that since the retailer is socially responsible, the makeup price strategy it adopts concerns much with the cost of CSR. If the retailer pays much for higher CSR, it will makeup more price to balance the cost and profit.

\section{Summary and Concluding Remarks}

In this paper, we have explored a socially responsible two-echelon supply chain by incorporating the cost of undertaking corporate social responsibility. It is assumed that in a two-layer supply chain consisting of the manufacturer and the retailer, the retailer practices CSR. While formulating the model, we have incorporated not only the effect of CSR in the form of consumer surplus in the socially responsible firm's profit function rather than the activities but also the cost for undertaking the social responsibility. We have discussed the retailer's CSR practice in two power structures, both manufacturer-Stackelberg game and retailer-Stackelberg game.

Firstly, whatever the channel structure is, when we incorporate the cost of retailer's undertaking CSR, the retailer's pursuit of CSR goal is inversely related to the pure profit. If the retailer puts more emphasis on CSR then its traditional profit decreases, which is the same as a supply chain not considering the cost in previous work. This helps us understand the difficulty in calling corporates for investing in social responsibility in the business world. We wonder if the government should increase subsidies to stimulate corporate's desire to undertake social responsibility. In addition, after 
incorporating the cost into the model, the retailer's welfare maximizing motive doesn't coordinate the socially concerned channel either with leading manufacturer or retailer, even though in the previous it has been examined the retailer's perfect welfare maximizing motive coordinates the socially concerned channel in the channel of profit maximizing manufacturer and socially concerned retailer.

Secondly, the retailer is set to be socially responsible. It is found that when the retailer plays the part as the leader of the channel, it will receive higher optimal profit. In other words, the retailer's leading role contributes to its CSR goal.

Lastly, the influence of the CSR cost to the channel member performs analogously in different power structures. Note that even if a particular firm in a supply chain is targeted for social responsibility, the pressure can be easily propagated to other members in the whole supply chain through their business transactions. In centralized decision, if the retailer holds lower CSR cost, the channel profit will increase with rising sense of CSR while the cost is higher, the profit will decrease when they pursue high level CSR quality. In Manufacturer- Stackelberg game, the total profit of the manufacturer and the retailer performs the same as centralized decision. The leading manufacturer's wholesale price will decrease with retailer's higher level CSR. With retailer leading the channel, similarly, when the retailer holds lower CSR cost, the channel profit will increase with rising sense of CSR while if the cost is higher, the profit will decrease when they pursue high quality of CSR. This result highlights the need for finding efficient ways of production and operation to keeping down the costs in the process of practicing CSR. Moreover, in this paper, we assume the retailer adapt the strategy of making up price. We have found that when the retailer pays higher for CSR, the makeup price will increase when it is for higher level CSR to compensate the cost of CSR. With the retailer price increasing, the order quantity will decrease and retailer need to keep the profit by rising price to make up the loss of quantity. But this may cause lower consumer purchasing and influence the buyers' decision. And when the cost is lower, the makeup price will decrease with the rising CSR. This findings display that some perceived consumer welfare matters much in the marketing of CSR-related product or service.

Although the present paper is developed based on some simple assumptions, several insightful results are derived. We think there are number of areas that deserve attention. First, it is assumed that the demand is linear in retail price. Although this type of demand pattern is fairly common in the literature, there are several price-sensitive and stochastic demands in the literature. Models may be developed by considering more complicated demand forms as mentioned above in comparison to the simple one assumed here. Second, the paper has not considered channel coordination. Models may be developed to examine effects of CSR on transfer pricing policies such as, quantity discount, and two-part tariff. Third, instead of considering any one firm is engaged in CSR, it may be assumed that both the firms are socially responsible. As such how do the firms apply policies, how CSR affect profits of the firms are some interesting questions, which need further investigation.

\section{Reference}

[1] Batterman, S.A., Amann, M., 1991. Targeted acid rain strategies including uncertainty. Journal of Environmental Management 32, 57-72.

[2] Quinn, B., 1999. E-system manages inventory to reduce risk.

[3] Qiu, Z., Prato, T., McCamley, F., 2001. Evaluating environmental risks using safety-first constraints. American Journal of Agricultural Economics 83, 402-413.

[4] Panda, S., 2014. Coordination of a socially responsible supply chain using revenue sharing contract. Transportation Research Part E Logistics \& Transportation Review 67, 92-104.

[5] Carter, C.R., Jennings, M.M., 2002. Social responsibility and supply chain relationships. Transportation Research Part E: Logistics and Trans-portation Review 38, 37-52. 
[6] Murphy, P.R., Poist, R.F., 2002. Socially responsible logistics: an exploratory study. Transportation Journal, 23-35.

[7] Ganesan, S., George, M., Jap, S., Palmatier, R.W., Weitz, B., 2009. Supply chain management and retailer performance: emerging trends, issues, and implications for research and practice. Journal of Retailing 85, 84-94.

[8] Sen, S., Bhattacharya, C.B., 2001. Does doing good always lead to doing better? consumer reactions to corporate social responsibility. Journal ofmarketing Research 38, 225-243.

[9] San, G.S., Pujawan, I.N., 2012. Closed-loop Supply Chain with Remanufacturing: A Literature Review. Ph.D. thesis. Petra Christian University.

[10Amaeshi, K.M., Osuji, O.K., Nnodim, P., 2008. Corporate social responsibility in supply chains of global brands: A boundaryless responsibility? clarifications, exceptions and implications. Journal of Business ethics 81, 223-234.

[14] Bowen, H. R. (1953). Social responsibilities of businessman. New York: Harper \& Row.

[12] Kaysen, C.1957 “The social significance of the modern corporation.” American Economic Review, 47: 311-319.

[13] Friedman, M.1970 “The social responsibility of business is to increase its profits.” New York Times Magazine, 13 September: 32-33.

[14] Margolis, J. D., and J. P. Walsh 2003 “Misery loves companies: Rethinking social initiatives by business.” Administrative Science Quarterly, 48: 268-305.

[15] McWilliams, A., and D. Siegel 2001 “Corporate social responsibility: A theory of the firm perspective.” Academy of Management Review, 26: 117-127.

[16] Enderle, G., Murphy, P.E., 2009. Ethics and corporate social responsibility for marketing in the global marketplace. The SAGE handbook of

international marketing , 504-531.

[17] Maignan, I., Ferrell, O., 2004. Corporate social responsibility and marketing: An integrative framework. Journal of the Academy of Marketing

science 32, 3-19.

[18] Brammer, S., Hoejmose, S., Millington, A., 2011. Managing sustainable global supply chains a systematic review of the body of knowledge. network for business sustainability.

[19] Ellen, P.S., Mohr, L.A., Webb, D.J., 2000. Charitable programs and the retailer: do they mix? Journal of retailing 76, 393-406.

[20] Du, S., Bhattacharya, C., Sen, S., 2011. Corporate social responsibility and competitive advantage: Overcoming the trust barrier. Management Science 57, 1528-1545.

[21] Turban, D.B., Greening, D.W., 1997. Corporate social performance and organizational attractiveness to prospective employees. Academy of management journal 40, 658-672.

[22] Brammer, S.J., Pavelin, S., 2006. Corporate reputation and social performance: The importance of fit. Journal of Management Studies 43, 435-455.

[23] Lindgreen, A., Swaen, V., Maon, F., Eltantawy, R.A., Fox, G.L., Giunipero, L., 2009. Supply management ethical responsibility: reputation and performance impacts. Supply Chain Management: An International Journal 14, 99-108. 
[24] Fombrun, C., Shanley, M., 1990. What's in a name? reputation building and corporate strategy. Academy of management Journal 33, 233-258.

[25] Stanwick, P.A., Stanwick, S.D., 1998. The relationship between corporate social performance, and organizational size, financial performance, and environmental performance: An empirical examination. Journal of business ethics 17, 195-204.

[26] Fombrun, C.J., 2001. Corporate reputations as economic assets. The Blackwell handbook of strategic management , 289-312.

[27] Husted, B.W., 2005. Risk management, real options, corporate social responsibility. Journal of Business Ethics 60, 175-183.

[28] Bhattacharya, C.B., Sen, S., 2004. Doing better at doing good: When, why, and how consumers respond to corporate social initiatives. California management review 47, 9-24.

[29] Carter, C.R., Jennings, M.M., 2002. Social responsibility and supply chain relationships. Transportation Research Part E: Logistics and Transportation Review 38, 37-52

[30] Carter, C.R., Jennings, M.M., 2004. The role of purchasing in corporate social responsibility: a structural equation analysis. Journal of business Logistics 25, 145-186.

[31] Bloemhof-Ruwaard, J.M., Van Beek, P., Hordijk, L., Van Wassenhove, L.N., 1995. Interactions between operational research and environmental management. European journal of operational research $85,229-243$.

[32] Ni, D., Li, K.W., 2012. A game-theoretic analysis of social responsibility conduct in two-echelon supply chains. International Journal of Production Economics 138, 303-313.

[33] Xiao, T., Yang, D., 2008. Price and service competition of supply chains with risk-averse retailers under demand uncertainty. International Journal of Production Economics 114, 187-200.

[34] Tsay, A.A., Agrawal, N., 2000. Channel dynamics under price and service competition. Manufacturing \& Service Operations Management 2, 372-391.

[35] Gurnani, H., Erkoc, M., Luo, Y., 2007. Impact of product pricing and timing of investment decisions on supply chain co-opetition. European Journal of Operational Research 180, 228-248.

[36] Lambertini, L., Tampieri, A., 2010. Corporate social responsibility in a mixed oligopoly .

[37] Goering, G.E., 2007. The strategic use of managerial incentives in a non-profit firm mixed duopoly. Managerial and decision economics 28, 83-91.

[38] Goering, G.E., 2008. Welfare impacts of a non-profit firm in mixed commercial markets. Economic Systems 32, 326-334.

[39] Kopel, M., Brand, B., 2012. Socially responsible firms and endogenous choice of strategic incentives. Economic Modelling 29, 982-989.

[40] Hua Z, Li S. Impacts of demand uncertainty on retailer's dominance and manufacturer-retailer supply chain cooperation. Omega 2008; 36:697-714.

[41] Raju J, Zhang ZJ. Channel coordination in the presence of a dominant retailer. Marketing Science 2005; 24:254-62.

[42] Iyer G, Villas-Boas JM. A bargaining theory of distribution channels. Journal of Marketing Research 2003; 40(1):80-100.

[43] Jian-Cai Wang, Amy Hing-Ling Lau, Hon-Shiang Lau, Dollar vs. percentage markup pricing schemes under a dominant retailer, European Journal of Operational Research, 227 (2013) 471-482 